\title{
ANÁLISE DA POSSIBILIDADE DE INSCRIÇÃO NOS QUADROS DA ORDEM DOS ADVOGADOS DO BRASIL (OAB) E A INIDONEIDADE MORAL EM RAZÃO DE VIOLÊNCIA CONTRA MULHER
}

\author{
ANALYSIS OF THE POSSIBILITY OF \\ REGISTRATION WITHIN THE LAWS OF BRAZIL'S \\ LAWYERS (OAB) AND MORAL INIDONEITY \\ IN VIEW OF VIOLENCE AGAINST WOMEN
}

Mayara de Sousa Alano ${ }^{1}$

Resumo: A finalidade deste trabalho é analisar a possibilidade da inscrição do requerente nos quadros da Ordem dos Advogados do Brasil (OAB) por inidoneidade moral em razão de violência contra a mulher, discorrendo acerca da Súmula $n^{\circ} 09$ do Conselho Pleno do Conselho Federal da Ordem dos Advogados do Brasil (CFOAB). A natureza da pesquisa, quanto ao nível, foi exploratória e, no que se refere à sua abordagem, qualitativa. $\mathrm{O}$ procedimento utilizado para a coleta de dados foi documental e bi- bliográfico. O método de abordagem foi o dedutivo. Constatou-se divergência na doutrina acerca do trânsito em julgado na esfera criminal para que possa haver o impedimento da inscrição nos quadros da OAB, bem como a ausência de uma definição a respeito da inidoneidade moral e do crime infamante. Confundem-se, muitas vezes, os procedimentos a serem adotados, quando da inidoneidade praticada pelo requerente à inscrição e quando da inidoneidade praticada por advogado, bem como o procedimento quando o

1 Bacharel em Direito pela Universidade do Sul de Santa Catarina (Unisul).E-mail: mayaraalano@hotmail.com 
crime ou o crime infamante é praticado pelo requerente à inscrição e quando o crime ou crime infamante é praticado por advogado. Conclui-se que a Súmula $n^{0}$ 09, aprovada para proporcionar mais estabilidade ao ordenamento jurídico e auxiliar na interpretação de casos semelhantes, deixa grandes lacunas com determinados termos utilizados em sua redação, mais precisamente quanto aos conceitos de inidoneidade moral e crime infamante, bem como os seus procedimentos, pois tanto o Estatuto da Advocacia quanto o CFOAB não definem tais conceitos, podendo gerar uma aplicação desacertada ou abusiva para uma das partes.

Palavras-chave: Violência contra as mulheres. Inidoneidade moral. Inscrição nos quadros da OAB.

Abstract: The purpose of this paper is to analyze the possibility of the applicant's enrollment in the OAB staff due to moral disadvantage due to violence against women, discussing the Precedent No. 09 of the Federal Council of the Brazilian Bar Association (CFOAB). The nature of the research, in terms of level, was exploratory and, in terms of its approach, qualitative. The procedure used for data collection was documentary and bibliographic. The approach method was deductive. There was a divergence in the doctrine about the unappealable transit in the criminal sphere so that there may be the impediment of enrollment in the OAB staff, as well as the absence of a definition regarding the moral unfairness and the infamous crime. The procedures to be adopted are often confused, when the applicant is unfit to apply and when the lawyer is unfit, as well as the procedure when the crime or infamous crime is practiced by the applicant to the application and when the crime or infamous crime is committed by a lawyer. It is concluded that Precedent No. 09, approved to provide greater stability to the legal system and assist in the interpretation of similar cases, leaves great gaps with certain terms used in its wording, more precisely regarding the concepts of moral unfairness and infamous crime, as well as its procedures, since both the Laws of the Advocacy and the CFOAB do not define such concepts, and may generate a wrong or abusive application for one of the parties.

Keywords: Violence against women. Moral Inidoneity. Enrollment in the OAB staff. 


\section{INTRODUÇÃO}

A aprovação da Súmula no 09/2019 pelo Conselho Pleno do CFOAB, no dia 18 de março de 2019, faz subsistir algumas divergências e questionamentos acerca da sua aplicabilidade, principalmente no que se refere à ausência de análise por parte do Poder Judiciário. É importante transcrevê-la a fim de examinar alguns pontos a serem debatidos:

INIDONEIDADE MORAL. VIOLÊNCIA CONTRA A MULHER. ANÁLISE DO CONSELHO SECCIONAL DA OAB. Requisitos para a inscrição nos quadros da Ordem dos Advogados do Brasil. Inidoneidade moral. A prática de violência contra a mulher, assim definida na "Convenção Interamericana para Prevenir, Punir e Erradicar a Violência contra a Mulher - 'Convenção de Belém do Pará' (1994)", constitui fator apto a demonstrar a ausência de idoneidade moral para a inscrição de bacharel em Direito nos quadros da OAB, independente da instância criminal, assegurado ao Conselho Seccional a análise de cada caso concreto. (CONSELHO FEDERAL DA ORDEM DOS ADVOGADOS DO BRASIL, 2019).

A Súmula em questão trata a respeito da violência doméstica ou familiar contra a mulher, nos moldes da Lei $\mathrm{n}^{\mathrm{o}}$ 11.340/2006, mais conhecida como Lei Maria da Penha (LMP), a qual exige alguns requisitos para sua aplicação, sendo que a violência necessita ser de gênero e em desfavor da mulher, ainda, no âmbito doméstico, familiar ou em relação íntima de afeto (BRASIL, 2006).

A violência contra a mulher é um problema global, o qual atinge diretamente a esfera dos direitos humanos, assim "ao longo da história as mais graves violações aos direitos humanos tiveram como fundamento a dicotomia do 'eu versus o outro' em que a diversidade era captada como elemento para aniquilar direitos." (BARCELLOS et al., 2019, p. 169). O próprio 
art. $6^{\circ}$ da LMP preceitua que tal violência "constitui uma das formas de violação dos direitos humanos." (BRASIL, 2006).

A Súmula em discussão tem por objetivo resguardar, notadamente, a parte mais vulnerável da relação. Assim, nasce um empecilho contra o (a) ofensor (a) que está pretendendo realizar a inscrição e entrar para os quadros da $\mathrm{OAB}$, visto que nem sempre a violência contra a mulher constitui um delito, podendo tão somente constituir uma conduta que demonstra a falta de idoneidade moral para o exercício da advocacia.

Conforme disposto no art. $8^{\circ}$, VI, do Estatuto da Advocacia e a Ordem dos Advogados do Brasil (EAOAB), para a inscrição como advogado (a), exigem-se alguns requisitos, dentre eles, a idoneidade moral (BRASIL, 1994).

No que tange à idoneidade moral, trata-se de um requisito subjetivo para inscrição como advogado (a). De acordo com Arbex e Zakka (2012, p. 30), "O cumprimento do requisito subjetivo da idoneidade moral impõe ao candidato a exercer a advocacia uma vida pregressa ilibada".

O conselho competente pode declarar ausente o requisito da idoneidade moral, observando o processo disciplinar, conforme dispõem os $\S \S 3^{\circ}$ e $4^{\circ}$ do art. $8^{\circ}$ do $\mathrm{EAOAB}^{2}$.

Já em relação ao crime infamante, nas palavras de Lôbo (2017, p. 95), compreende-se como aquele:

[...] que provoca o forte repúdio ético da comunidade geral e profissional, acarretando desonra para seu autor,

$2 \S 3^{\circ} \mathrm{A}$ inidoneidade moral, suscitada por qualquer pessoa, deve ser declarada mediante decisão que obtenha no mínimo dois terços dos votos de todos os membros do conselho competente, em procedimento que observe os termos do processo disciplinar.

$\S 4^{\circ}$ Não atende ao requisito de idoneidade moral aquele que tiver sido condenado por crime infamante, salvo reabilitação judicial (BRASIL, 1994). 
e que pode gerar desprestígio para a advocacia se for admitido seu autor a exercê-la. Infamante é conceito indeterminado, de delimitação difícil, devendo ser concretizado caso a caso pelo Conselho Seccional.

Ao examinar o $\S 4^{\circ}$ do art. $8^{\circ}$ do $\mathrm{EAOAB}$, num primeiro momento, ao se referir ao crime infamante, este coloca em dúvida se está conceituando a idoneidade moral ou definindo que a prática de crime infamante é uma das causas de inidoneidade moral.

É necessário apreciar cada caso concreto. Segundo entendimento de Arbex e Zakka (2012, p. 30), o outro requisito contido no $\S 4^{\circ}$ do art. $8^{\circ}$ não atinge ou interfere no requisito da idoneidade moral, pois são independentes e de naturezas diversas para sua constatação. Os mesmos autores compreendem que o crime infamante depende do trânsito em julgado na jurisdição do Poder Judiciário.

Assim, caberá analisar se a violência contra a mulher constitui crime infamante e/ou da inidoneidade moral, julgados pelo Poder Judiciário e/ou em processo ético-disciplinar, com observância ao princípio da presunção da inocência e da independência das instâncias.

\section{ADVOCACIA COMO PROFISSÃO E VIOLÊNCIA CONTRA A MULHER}

Advocacia é uma das profissões essenciais à administração da justiça, conforme estabelecem os arts. $2^{\circ}$ do EAOAB e do Código de Ética e Disciplina da OAB (CED), respectivamente, tendo como principal objetivo a defesa de pessoas, direitos e interesses (LÔBO, 2017, p. 19).

$\mathrm{O}$ advogado é aquele que busca a realização da justiça. A própria palavra deriva do latim ad-vocatus, ou seja, o que é chamado em defesa (LUZ, 2004, p. 22). 
Luz (2004, p. 22) afirma que, nos primórdios, a defesa pelos necessitados se dava em razão da solidariedade, sem qualquer intenção de benefício próprio. Por isso, a advocacia nasceu da necessidade de ajudar os mais fracos, prestando serviços à verdade, ao direito e à justiça.

A Constituição da República Federativa do Brasil de 1988 (CRFB/1988) estabelece em seu art. 133 que "O advogado é indispensável à administração da justiça, sendo inviolável por seus atos e manifestações no exercício da profissão, nos limites da lei." (BRASIL, 1988).

Diante do exposto, compreende-se que a advocacia é indispensável para a defesa. Sem ela, é impossível resolver as lides ou praticar quaisquer outras atividades previstas no art. $1^{\circ}$ do EAOAB e outros atos que exigem a presença do advogado.

Tendo em vista que o advogado é indispensável à administração da justiça e exerce uma função social, não há como permitir que alguém ingresse nos quadros da $\mathrm{OAB}$ sem preencher todos os requisitos necessários para inscrição, requisitos estes que se encontram previstos no art. $8^{\circ}$ do EAOAB.

A prática de violência contra a mulher compõe fator apto a demonstrar a inidoneidade moral e provocar o impedimento da inscrição nos quadros da OAB, pois, segundo Lôbo (2016, p. 93), “[...] não são compatíveis com a idoneidade moral as atitudes e comportamentos imputáveis ao interessado, que contaminarão necessariamente sua atividade profissional, em desprestígio da advocacia”. Não faria sentido permitir que alguém que é considerado inidôneo ingresse nos quadros da $\mathrm{OAB}$, pois este não cumpriria e não zelaria pelos deveres impostos pela Ordem.

$\mathrm{O} \S 8^{\circ}$ do art. 226 da CRFB/1988 determina que "O Estado assegurará a assistência à família na pessoa de cada um dos 
que a integram, criando mecanismos para coibir a violência no âmbito de suas relações." (BRASIL, 1988).

Ademais, de acordo com Gama (2015, p. 5),

[...] a Convenção Interamericana para Prevenir, Punir e Erradicar a Violência contra a mulher insere-se no sistema regional especial de proteção aos direitos humanos. Foi aprovada pela Assembleia Geral da Organização dos Estados Americanos em 9 e junho de 1994. Tal convenção foi incorporada ao ordenamento jurídico brasileiro com a promulgação do Decreto Presidencial 1.917 , de $1^{\circ}$ de agosto de 1996 . Trata-se de tratado internacional que vincula o Brasil não só perante os demais estados signatários, mas também internacionalmente, possibilitando sua plena aplicação e execução ante o Poder Judiciário.

Ainda se busca incansavelmente pela efetividade dos direitos das mulheres, tendo em vista que os documentos internacionais de direitos humanos e as Constituições proclamam uma igualdade que é compreendida em seu aspecto formal e longe está de alcançar a igualdade real entre homens e mulheres (CUNHA; PINTO, 2019, p. 41).

Assim, destaca-se que os tratados internacionais de diretos humanos assumem uma importante dimensão no que diz respeito à existência, à garantia e à efetividade dos direitos humanos das mulheres, pois as normas internas dos Estados não são suficientes na busca da vivência da dignidade da pessoa humana, especialmente, a dignidade da mulher (ESPÍNDOLA, 2018, p. 31).

Os diplomas internacionais contribuíram para a formação dos direitos humanos das mulheres (ESPÍNDOLA, 2018, p. 34), em especial a Convenção Interamericana para Prevenir, Punir e Erradicar a Violência contra a Mulher. 
A partir da Declaração Universal dos Direitos Humanos, no ano de 1948, passou-se à positivação dos Direitos Humanos no Direito Internacional, mediante a adoção de inúmeros tratados internacionais voltados à proteção de direitos fundamentais. Os Pactos ou as Convenções Internacionais buscam responder a determinadas violações de direitos humanos, como a discriminação racial, a discriminação contra as mulheres, entre outras formas (MELLO; PAIVA, 2019, p. 40).

A Convenção Interamericana foi o primeiro tratado internacional de direitos humanos que utilizou o termo gênero e reconheceu que a violência contra a mulher não depende de idade, raça, religião, classe etc., atingindo um elevado número de mulheres, independentemente de sua condição (BIANCHINI, 2018, p. 131). Trouxe também um grande avanço na proteção internacional dos direitos humanos das mulheres, afirmando que a violência contra a mulher viola os direitos humanos, a dignidade da pessoa humana e as liberdades fundamentais, reconhecendo, ainda, que é uma manifestação das relações de poder historicamente desiguais entre mulheres e homens (BRASIL, 1996).

É evidente que a Convenção Interamericana para Prevenir, Punir e Erradicar a Violência contra a Mulher e a LMP são os principais instrumentos que tratam acerca da violência contra a mulher, visto que esta constitui um grave problema de saúde pública. Por isso, faz-se necessário estar constantemente buscando meios para prevenir, punir e erradicar toda forma de violência contra a mulher.

Dessa maneira, se o (a) candidato (a) praticar violência contra a mulher, viola os direitos humanos, bem como fere a idoneidade moral, de modo a contaminar a atividade profissional e se tornar inidôneo(a) para o exercício da advocacia, impedindo sua inscrição nos quadros da $\mathrm{OAB}$, devendo, é claro, ser analisado cada caso concreto. 


\section{INIDONEIDADE MORAL COMO IMPEDIMENTO DE INSCRIÇÃO NOS QUADROS DA ORDEM DOS ADVOGADOS DO BRASIL (OAB) EM RAZÃO DE VIOLÊNCIA CONTRAA MULHER}

É importante explanar os conceitos de idoneidade moral e inidoneidade moral e as diferenças entre a idoneidade moral exigida para a inscrição e a inidoneidade moral mencionada como infração disciplinar e superveniente à inscrição; os conceitos de crime infamante e as diferenças entre o crime infamante como requisito para inscrição e o crime infamante mencionado como infração disciplinar e superveniente à inscrição; a competência para apreciar a inidoneidade moral e o crime infamante e o processo disciplinar na OAB; a independência entre as instâncias criminal e administrativa nas condutas ou nos crimes praticados no contexto doméstico ou familiar ou nas relações íntimas de afeto contra a mulher.

Um dos requisitos para a inscrição nos quadros da $\mathrm{OAB}$, a idoneidade moral, encontra-se previsto no inciso VI do art. $8^{\circ}$ do EAOAB. A falta desse requisito, conforme estabelece a própria Súmula n ${ }^{\circ}$ 09/2019 do Conselho Pleno do CFOAB, é fator impeditivo para a inscrição do requerente nos quadros da $\mathrm{OAB}$.

Nas palavras de Gonzaga, Neves e Beijato Junior (2019, p. 60), "Devemos considerar como idôneo moralmente o sujeito que age de forma escorreita. $\mathrm{O}$ contrário é o inidôneo moral, que para a lei é quem pratica qualquer tipo de crime infamante que atente contra a advocacia."

No $\S 3^{\circ}$ do art. $8^{\circ}$ do EAOAB, está estabelecido que a inidoneidade deverá ser declarada mediante decisão do conselho competente.

Art. $8^{\circ}$ Para inscrição como advogado é necessário:

$[\ldots]$ 
$\S 3^{\circ} \mathrm{A}$ inidoneidade moral, suscitada por qualquer pessoa, deve ser declarada mediante decisão que obtenha no mínimo dois terços dos votos de todos os membros do conselho competente, em procedimento que observe os termos do processo disciplinar.

[...] (BRASIL, 1994).

Lôbo (2017, p. 2017) não destoa desse entendimento, afirmando que "[...] não são compatíveis com a idoneidade moral atitudes e comportamentos, que contaminarão necessariamente sua atividade profissional $[\ldots]$ ".."

O conceito de idoneidade moral possui alto grau de subjetivismo, tendo em vista que está diretamente ligado às qualidades de respeitabilidade, de honra, de dignidade, de seriedade e de bons costumes, por isso o EAOAB presume moralmente idôneos aqueles que requeiram suas inscrições nos quadros da OAB (VIEIRA; CERNOV, 2016, p. 70).

Rachid (2019) entende que, na idoneidade moral, os valores se mostram essenciais, assim como a honestidade e a dignidade, que devem pautar o profissional do direito. Segundo ele, além dos casos envolvendo violência doméstica, outros casos foram observados pela OAB que justificaram a inidoneidade moral, concluindo-se que não existe um rol taxativo e, por isso, o caso concreto deverá ser julgado pelo conselho competente.

Segundo Batista (2010), a OAB procura reprimir a inscrição daqueles que praticam atos lesivos à imagem da Advocacia, entre os quais se encontra a prática de qualquer ato contra os bons costumes, a prática criminal ou contravencional, inclusive a prática de crime considerado infamante pela classe de advogados.

Conclui-se, portanto, diante do que foi exposto, que não há um conceito de idoneidade moral e inidoneidade moral, visto que cada caso terá que ser apreciado detalhadamente 
pelo conselho competente, ou seja, faz-se necessária uma análise justa da conduta, bem como da pessoa requerente à inscrição. Assim também são os casos de violência praticada nos moldes da LMP, os quais serão declarados mediante decisão de dois terços dos votos de todos os membros do conselho competente.

É relevante atentar-se que a idoneidade moral de que trata a Súmula $n^{\circ}$ 09/2019 diz respeito ao inciso VI do art. $8^{\circ}$ do $\mathrm{EAOAB}$, ou seja, quando é tratada como um requisito para a inscrição do interessado; já a inidoneidade moral prevista no inciso XXVII do art. 34 do EAOAB, como infração disciplinar, é relativa a fatos posteriores à inscrição, ou seja, quando cometidos por advogados. Em suma, a idoneidade é tanto um requisito para o ingresso nos quadros da $\mathrm{OAB}$ quanto para $\mathrm{o}$ exercício da profissão.

Nesse sentido, os julgados do CFOAB expõem sobre o indeferimento da inscrição do requerente nos quadros da $\mathrm{OAB}$, entendendo que tal indeferimento não depende de decisão judicial com trânsito em julgado ${ }^{3}$.

Embora a inidoneidade prevista como infração disciplinar não seja limitada à prática de crimes, deduz-se que, pelo fato de ser uma infração disciplinar, exige-se certa gravidade da conduta. Por isso, o que ocorre, na maioria das vezes, é a prática de crimes pelos advogados. Nesse sentido, compreende o CFOAB acerca da inidoneidade superveniente à inscrição, exigindo o trânsito em julgado da sentença penal condenatória, em caso de crimes ${ }^{4}$.

Cabe ressaltar que o advogado poderá cometer ato que não seja tipificado como crime, mas que é contrário à moral adequada para desempenho de sua função. Assim, será excluído dos

3 Recurso n. ${ }^{\circ} 49.0000 .2016 .004647-4 /$ pca.

4 Recurso n. ${ }^{\circ} 49.0000 .2015 .009832-1 /$ sca-stu. 
quadros da $\mathrm{OAB}$, nos termos do art. 38, II e parágrafo único, do EAOAB, devendo, nesse caso, ser declarada a inidoneidade por dois terços dos votos dos membros do conselho competente. Do mesmo modo, o requerente à inscrição poderá ser considerado inidôneo, conforme aduz o $\S 3^{\circ}$ do art. $8^{\circ}$ do EAOAB.

É relevante mencionar que a inidoneidade moral que veda o pedido de inscrição não pode ser debatida com base nos mesmos princípios do processo ético pela infração disciplinar do art. 34 do EAOAB, inclusive no que tange ao ônus da prova e à aplicação do princípio da presunção da inocência, pois, nos casos em que o advogado se tornar moralmente inidôneo, compete à $\mathrm{OAB}$ provar em processo disciplinar, bem como milita a favor do advogado o princípio da presunção da inocência (RAMOS, 2017, p. 178-179).

Batista (2010) entende que "A OAB independe do trânsito em julgado de sentença penal condenatória para declarar a inidoneidade daquele bacharel ou advogado [...]".

No que se refere ao crime infamante, é importante ressaltar que a Súmula objeto de estudo não menciona o crime infamante, mas, por possuir um conceito indeterminado, depreende-se que algumas formas de violência contra a mulher podem ser consideradas crimes infamantes e, portanto, tornam o requerente moralmente inidôneo e obstam a inscrição dele, nos termos do $\S 4^{\circ}$ do art. $8^{\circ}$ do EAOAB.

Não existe uma definição de crime infamante no ordenamento jurídico, da mesma forma que de idoneidade moral, sendo que ambos os institutos possuem um conceito indeterminado. Gonzaga, Neves e Beijato Junior (2019, p. 61) expõem que:

[...] devemos entender que o conceito de crime infamante não se relaciona apenas com o bem jurídico tutelado pelo crime praticado, muito menos com a pena que lhe é aplicada, mas sim o impacto e repercussão que a condenação 
por este crime traz a toda classe advocatícia em seu exercício profissional, trazendo a ela desprestígio e desonra.

Nas palavras de Ramos (2017, p. 519), o crime infamante "[...] é todo aquele que atinge a boa fama, ou seja, capaz de desacreditar o advogado, macular o conceito de advocacia".

Para Arbex e Zakka (2012, p. 116), os "Crimes infamantes são aqueles que acarretam a desonra e a indignidade do advogado, como resultado de repulsa extrema da sociedade ante o comportamento reprovável do agente".

O crime infamante não é qualquer crime, mas sim aquele que provoca forte repúdio ético da comunidade geral e profissional, gerando desprestígio para a advocacia, como, por exemplo, o crime de estelionato e falsificação documental (LÔBO, 2017, p. 95).

Como mencionado alhures, os crimes infamantes não estão previstos ou especificamente tipificados na legislação penal brasileira. São exemplos de crimes infamantes, "[...] pedofilia, abusos sexuais, cometimento de crimes reiterados por formação de quadrilha, entre outros que causem absoluta repulsa social [...]." (GONZAGA; NEVES; BEIJATO JUNIOR, 2019, p. 186).

De modo bem claro, Machado et al $(2015$, p. 330) criticam a inexistência da definição de crime infamante, alegando que "Há quem negue por completo a aplicabilidade desse dispositivo, sob o argumento de que a Lei não define o que é crime infamante".

Depreende-se que não resta definido o conceito de crime infamante, mas a maioria o define como sendo aquele que repercute contra a moral da advocacia (SOARES NETO, 2017). Assim, pode-se concluir que a violência perpetrada contra a mulher nos moldes da LMP, para ser considerada crime infamante, deverá macular a advocacia e atingir a boa fama do requerente à inscrição. 
É imperioso destacar que o crime infamante mencionado no $\S 4^{\circ}$ do art. $8^{\circ}$ do EAOAB trata-se de hipótese anterior à inscrição, ou seja, requisito para inscrição; já o crime infamante previsto no inciso XXVIII do art. 34 do EAOAB constitui infração disciplinar relativa a fatos posteriores à inscrição, isto é, crimes infamantes cometidos por advogados.

$\mathrm{O}$ crime infamante é citado pela primeira vez no EAOAB no $\S 4^{\circ}$ do art. $8^{\circ}$, estabelecendo que "Não atende ao requisito de idoneidade moral aquele que tiver sido condenado por crime infamante, salvo reabilitação judicial." (BRASIL, 1994).

Vieira e Cernov (2016, p. 73) afirmam que, embora não se excluam outras hipóteses, o EAOAB estabelece como caso de inidoneidade moral a condenação por crime infamante, porém não é qualquer crime, e sim aquele que causa repúdio à comunidade em geral, em razão dos meios empregados ou das circunstâncias de seu cometimento. Nos casos do $\S 4^{\circ}$ do art. $8^{\circ}$ do $\mathrm{EAOAB}$, o CFOAB não tem exigido o trânsito em julgado da sentença penal condenatória ${ }^{5}$. Todavia, na prática de crime infamante superveniente à inscrição, o CFOAB tem exigido reiteradamente o trânsito em julgado da sentença penal condenatória ${ }^{6}$.

A respeito de a idoneidade moral ser requisito para a inscrição, deve-se observar o disposto no $\S 3^{\circ}$ do art. $8^{\circ}$ do EAOAB, o qual estabelece que a inidoneidade poderá ser suscitada por qualquer pessoa e declarada mediante decisão de dois terços dos membros do conselho competente, com observância ao processo disciplinar. Nesses casos, compete privativamente ao Conselho Seccional decidir sobre os pedidos de inscrição, conforme determina o art. 58, VII, do EAOAB (BRASIL, 1994).

\footnotetext{
5 Recurso n. ${ }^{\circ} 5.584 / 2001 /$ pca-rj.

Recurso n. ${ }^{\circ} 2008.08 .01108-05$.

6 Recurso n. ${ }^{\circ} 49.0000 .2012 .001798-5 /$ sca-ttu.

Recurso n. ${ }^{\circ} 0146 / 2005 /$ sca.
} 
O processo administrativo para averiguar a inidoneidade é incidental e prejudicial ao pedido de inscrição, suspendendo seu curso até o julgamento definitivo. Seguirá o rito do processo disciplinar (MACHADO et al., 2015, p. 113; VIEIRA; CERNOV, 2016, p. 70).

Nos casos de inidoneidade superveniente à inscrição (art. 34, XXVII, do EAOAB), ou seja, quando o advogado se tornar moralmente inidôneo, o processo ético pela infração disciplinar do art. 34 não pode ser debatido com base nos mesmos princípios que a inidoneidade moral que veda o pedido de inscrição. Isso porque, nesses casos, o ônus de provar a inidoneidade é da $\mathrm{OAB}$, observando-se o princípio da presunção da inocência em regular processo disciplinar, ao contrário dos casos de pedido de inscrição, em que, na dúvida, se preserva a sociedade (RAMOS, 2017, p. 178-179).

Portanto, quando o advogado se tornar moralmente inidôneo para o exercício da advocacia, aplicar-se-á a sanção disciplinar de exclusão, sendo necessária a manifestação favorável de dois terços dos membros do Conselho Seccional, conforme dispõe o parágrafo único do art. 38 do EAOAB.

Nas hipóteses de crime infamante praticado anteriormente à inscrição ( $\S 4^{\circ}$ do art. $8^{\circ}$ do EAOAB), a doutrina majoritária e o CFOAB entendem, na maioria dos casos, que não é necessário o trânsito em julgado da sentença penal condenatória, devendo ser declarado mediante decisão que obtenha no mínimo dois terços dos votos do conselho competente, nos termos do $\S 3^{\circ}$ do art. $8^{\circ}$ do EAOAB. Nesses casos, compete privativamente ao Conselho Seccional decidir sobre os pedidos de inscrição, conforme determina o art. 58, VII, do EAOAB (BRASIL, 1994).

Acerca do crime infamante previsto como infração disciplinar no art. 34, XXVIII, do EAOAB, ou seja, aquele praticado por advogados, a doutrina majoritária e o CFOAB entendem, na 
maioria dos casos, que há necessidade do trânsito em julgado da sentença penal condenatória, observando-se o disposto no parágrafo único do art. 38 do EAOAB, sendo, posteriormente, “[...] necessária a manifestação favorável de dois terços dos membros do Conselho Seccional competente." (BRASIL, 1994).

$\mathrm{O}$ processo disciplinar na $\mathrm{OAB}$ rege-se pelas regras previstas nos arts. 68 a 75 do EAOAB e pelas regras dos arts. 55 a 69 do CED.

Determina o art. 69 do CED que o advogado que tenha sofrido sanção disciplinar poderá requerer a reabilitação. Do mesmo modo, estabelece o art. 41 do EAOAB ao permitir que a reabilitação ocorra após um ano do cumprimento da sanção disciplinar (BRASIL, 1994; CONSELHO FEDERAL DA ORDEM DOS ADVOGADOS DO BRASIL, 2015). Essa regra também se aplica aos requerentes à inscrição, pois o próprio $\S 3^{\circ}$ do art. $8^{\circ}$ do EAOAB preceitua que o incidente de inidoneidade observará os termos do processo disciplinar, de tal sorte que aquele que teve o impedimento da inscrição poderá valer-se de novo pedido, por aplicação analógica do art. 41 do EAOAB (VIEIRA; CERNOV, 2016, p. 70).

Em sua parte final, a Súmula ${ }^{0}$ 09/2019 é bem clara ao estabelecer que o requerente à inscrição será impedido de se inscrever nos quadros da $\mathrm{OAB}$, independentemente de julgamento na instância criminal.

O princípio da independência das instâncias decorre da separação dos poderes, expresso no art. $2^{\circ}$ da CRFB/1988, o qual estabelece que "São Poderes da União, independentes e harmônicos entre si, o Legislativo, o Executivo e o Judiciário." (BRASIL, 1988).

Em regra, esse princípio estabelece que a punição administrativa não depende de processo criminal ou civil, devendo ser observado o devido processo legal e a ampla defesa. 
Salienta-se que o ilícito administrativo pode gerar repercussão na esfera penal, ou seja, quando constituir fato tipificado como crime, deverá ser analisado pelo Poder Judiciário, tornando indiscutível a questão na via administrativa. Todavia, se a repercussão for meramente administrativa, não há razões para acionar outras instâncias (MORESCO, 1998).

Ferreira (2013) argumenta que a própria Administração deveria aguardar o desfecho da apuração criminal para aplicar a sanção administrativa, haja vista que, para determinar o cometimento ou não de um crime, cabe exclusivamente ao Poder Judiciário.

No entanto, frisa-se que a inidoneidade moral não se limita tão somente à prática de crimes, devendo ser analisado cada caso concreto.

A sentença penal absolutória gerará reflexos na instância administrativa quando for provada a inexistência do fato, quando não houver provas sobre a existência do fato, quando não houver prova de que o réu concorreu para a infração penal, quando o réu sofreu coação irresistível, quando for comprovada a inimputabilidade do réu ou ainda em outros casos definidos pela lei penal. Entretanto, há casos em que a sentença absolutória não repercute na instância administrativa, como, por exemplo, quando o fato não constituir infração penal ou quando houver insuficiência, deficiência ou ineficiência de provas para a condenação, sendo que, nesses casos, há autonomia da instância administrativa para a apuração e aplicação das sanções disciplinares (MORESCO, 1998).

Adentrando mais precisamente no tema da pesquisa, Medina (2009) expõe que as infrações disciplinares do art. 34 do $\mathrm{EAOAB}$ requerem a instauração de processo ético disciplinar, podendo ser concluído independentemente do que venha a ser decidido no juízo criminal. Entretanto, o poder 
disciplinar não foge à regra da prevalência do juízo criminal diante dos fatos típicos perante o Direito Penal, como, por exemplo, a decisão judicial que conclui pela inexistência do fato ou pela negativa de autoria afeta à decisão a ser dada no processo administrativo.

A prática de crime (infamante ou não) pelo advogado é a única exceção ao princípio da independência das instâncias, pois o julgador, nesse caso, deverá suspender o processo éticodisciplinar até o julgamento da ação penal, isso em respeito ao princípio da presunção da inocência previsto no art. $5^{\circ}$, LVII, da CRFB/1988, o qual preceitua que "ninguém será considerado culpado até o trânsito em julgado de sentença penal condenatória." (MEDINA, 2009; BRASIL, 1988).

Vieira e Cernov (2016) compreendem que, embora exista a independência entre as esferas civil, penal e administrativa, a absolvição do advogado, na esfera penal, produz efeitos na esfera administrativa quando se negar a existência do crime ou de sua autoria. Do mesmo modo, se a punição disciplinar está fundada na prática de crime, esse não pode ser declarado no âmbito administrativo sem o trânsito em julgado da sentença penal condenatória.

Portanto, nem sempre a sentença proferida na instância criminal terá efeito sobre a instância administrativa, havendo, ainda, que se considerar a repercussão negativa sobre a classe de advogados e a sociedade em geral (MEDINA, 2009).

\section{CONCLUSÕES}

Buscou-se, de forma mais aprofundada, compreender a Súmula $n^{\circ}$ 09/2019 do Conselho Pleno do CFOAB. Inicialmente, algumas controvérsias e questionamentos surgiram no meio jurídico, principalmente no que se refere ao impedimento da inscrição do requerente sem que houvesse análise 
por parte do Poder Judiciário, utilizando-se, como principal argumento, a violação ao princípio da presunção da inocência, previsto no art. 5 , LVII, da CRFB/1988.

Ao longo da pesquisa, observou-se, além da problemática envolvendo o julgamento por parte da instância criminal quando a inidoneidade moral constitui crime ou crime infamante, que o EAOAB, o CFOAB, o RGEAOAB (Regulamento Geral do Estatuto da Advocacia e da Ordem dos Advogados do Brasil) ou qualquer outro diploma legal não delimitam os conceitos de inidoneidade moral e de crime infamante ou estabelecem um rol taxativo para tal, deixando grandes lacunas para julgamentos e interpretações abusivas.

Outrossim, é importante esclarecer que foram examinadas a idoneidade moral exigida como requisito para a inscrição nos quadros da $\mathrm{OAB}$ e a inidoneidade moral praticada pelo advogado e prevista como infração disciplinar e, ainda, a diferença entre o crime infamante como requisito para inscrição e o crime infamante mencionado como infração disciplinar e superveniente à inscrição. Nos casos de crimes ou crimes infamantes praticados por advogados, a doutrina majoritária compreende que devem ser submetidos a julgamento por parte do Poder Judiciário. Já no que se refere aos crimes ou crimes infamantes praticados pelos requerentes à inscrição, a doutrina majoritária e o CFOAB entendem que não há a necessidade do trânsito em julgado da sentença penal condenatória.

A presente pesquisa demonstrou ainda que as mulheres, ao longo da história, sofreram graves violações aos seus direitos, tanto que se passou a dar mais importância aos direitos humanos das mulheres, o que levou à aprovação da Súmula $n^{\circ}$ 09/2019 pelo Conselho Pleno do CFOAB.

A Súmula traz, em sua redação, que a prática de violência contra a mulher obsta a inscrição em razão de o requerente 
tornar-se moralmente inidôneo. Portanto, trata somente dos fatos praticados pelo requerente à inscrição e não dos fatos praticados por advogado. E é possível concluir que mesmo a conduta não tipificada em lei poderá impedir a inscrição por decisão que obtenha no mínimo dois terços dos votos de todos os membros do conselho competente. Frisa-se, ainda, que a prática de crime - infamante ou não - também poderá tornar o requerente moralmente inidôneo e obstará sua inscrição nos quadros da $\mathrm{OAB}$.

Em suas decisões, o CFOAB não tem exigido o trânsito em julgado na instância criminal para que haja o impedimento da inscrição do requerente que praticou crime, crime infamante ou qualquer conduta que o tornou moralmente inidôneo.

Há ainda que se considerar o princípio da independência das instâncias, o qual determina que a punição administrativa não depende de processo criminal ou civil.

No entendimento da autora, após aprofundar-se no estudo do tema em questão, esta chegou à conclusão de que, quando o fato constituir crime ou crime infamante praticado pelo requerente à inscrição, não há que se falar em análise por parte do Poder Judiciário, haja vista que a OAB exige alguns requisitos para inscrição e, se lhe faltar um deles, colocando em dúvida a idoneidade moral do requerente, preserva-se a sociedade. Não faria sentido a Ordem permitir que alguém que possui fatos duvidosos imputados em seu desfavor ingresse em seus quadros sem que antes haja a decisão que obtenha no mínimo dois terços dos votos de todos os membros do conselho competente.

\section{REFERÊNCIAS}

ARBEX, Sergei Cobra; ZAKKA, Rogério Marcus. Estatuto da advocacia, prerrogativas e ética. Barueri: Manole, 2012. 
BARCELlOS, Ana Paula de et al. Constitucionalismo feminista. Salvador: Juspudvm, 2019.

BATISTA, Joselito Alves. Idoneidade moral perante a OAB, exigida pelo inciso VI do artigo $8^{\circ}$ da Lei $n^{\circ} 8.906 / 1994$. Revista Jus Navigandi, Teresina, ano 15, n. 2409, 4 fev. 2010. Disponível em: https:// jus.com.br/artigos/14306/idoneidade-moral-perante-a-oab-exigida-pelo-inciso-vi-do-artigo-8-da-lei-n-8-906-1994. Acesso em: 2 nov. 2019.

BIANCHINI, Alice. Lei Maria da Penha: lei n. 11.340/2006: aspectos assistenciais, protetivos e criminais da violência de gênero. 4. ed. São Paulo: Saraiva Jur, 2018.

BRASIL. [Constituição (1988)]. Constituição da República Federativa do Brasil de 1988. Brasília: DF: Presidência da República, 1988. Disponível em: http://www.planalto.gov.br/ccivil_03/constituicao/ constituicao.htm. Acesso em: 18 abr. 2019.

BRASIL. Lei $\mathrm{n}^{0} 1.973$, de $1^{\circ}$ de agosto de 1996. Promulga a Convenção Interamericana para Prevenir, Punir e Erradicar a Violência contra a Mulher, concluída em Belém do Pará, em 9 de junho de 1994. Brasília: DF; Presidência da República, 1996. Disponível em: http://www. planalto.gov.br/ccivil_03/decreto/1996/D1973.htm. Acesso em: 11 set. 2019.

BRASIL. Lei $\mathbf{n}^{\mathbf{0}} \mathbf{1 1 . 3 4 0 ,}$ de 7 de agosto de 2006. Cria mecanismos para coibir a violência doméstica e familiar contra a mulher, nos termos do $\S 8^{\circ}$ do art. 226 da Constituição Federal, da Convenção sobre a Eliminação de Todas as Formas de Discriminação contra as Mulheres e da Convenção Interamericana para Prevenir, Punir e Erradicar a Violência contra a Mulher; dispõe sobre a criação dos Juizados de Violência Doméstica e Familiar contra a Mulher; altera o Código de Processo Penal, o Código Penal e a Lei de Execução Penal; e dá outras providências. Brasília: DF; Presidência da República, 2006. Disponível em: http:// www.planalto.gov.br/ccivil_03/_ato2004-2006/2006/lei/111340.htm. Acesso em: 18 abr. 2019.

BRASIL. Lei no 8.906, de 4 de julho de 1994. Dispõe sobre o Estatuto da Advocacia e a Ordem dos Advogados do Brasil (OAB). Brasília: DF; Presidência da República, 1994. Disponível em: http://www.planalto.gov.br/ccivil_03/Leis/L8906.htm. Acesso em: 18 abr. 2019.

CONSELHO FEDERAL DA ORDEM DOS ADVOGADOS DO 
BRASIL. Recurso 49.0000.2012.001798-5/SCA-TTU. Processo ético. Recursos ao Conselho Federal da Ordem dos Advogados do Brasil. Advogado. Para exclusão de advogado dos quadros da OAB em representação promovida sob a eiva de cometimento de crime infamante (artigo 34, inciso XXVIII, do EAOAB), exige como pressuposto, tenha a sentença penal condenatória transitado em julgado. [...] Relator: Renato da Costa Figueira, 17 de abril de 2012. Disponível em: https://www.oab. org.br/jurisprudencia/detementa/9489?title $=49-0000-2012-001798$ $5 \&$ search $=\% \mathrm{C} 3 \% 80 \% 20 \mathrm{~m} \% \mathrm{C3} \% \mathrm{ADngua} \% 20 \mathrm{do} \% 20 \operatorname{tr} \% \mathrm{C3} \% \mathrm{~A} 2 \mathrm{nsi}-$ to $\% 20 \mathrm{em} \% 20$ julgado $\% 20 \mathrm{a} \% 20$ condena $\% \mathrm{C} 3 \% \mathrm{~A} 7 \% \mathrm{C} 3 \% \mathrm{~A} 3 \mathrm{o}$. Acesso em: 3 nov. 2019.

CONSELHO FEDERAL DA ORDEM DOS ADVOGADOS DO BRASIL. Recurso No 0146/2005/SCA. É nula a decisão condenatória em processo ético-disciplinar quando o fato imputado ao advogado constitui crime e acha-se sub judice, na Vara Criminal competente, instância adequada para a sua apuração, tanto mais quando, na esfera administrativa, a prova revelou-se insuficiente para caracterizar a infração. [...] Relator: Paulo Roberto de Gouvêa Medina, 07 de fevereiro de 2006. Disponível em: https://www.oab.org.br/jurisprudencia/detementa/2970?title=0146-2005-sca\&search=vara $\% 20$ criminal $\% 20$ nula. Acesso em: 3 nov. 2019.

CONSELHO FEDERAL DA ORDEM DOS ADVOGADOS DO BRASIL. Recurso no 5.584/2001/PCA-RJ. Idoneidade moral - Condenação por crime de homicídio qualificado, com perda de cargo público. Livramento condicional. Não é possível a inscrição nos quadros da OAB, seja como estagiário, seja como advogado, de candidato que foi condenado por homicídio duplamente qualificado, com a decorrente perda de cargo público, face a ausência do requisito da idoneidade moral, estabelecida no art. $8^{\circ}$, VI, e $\S 4^{\circ}$ da Lei 8.906, de 1994. O livramento condicional apenas suspende a execução da pena privativa de liberdade mas não os efeitos da condenação. Relator: Reginald Delmar Hintz Felker, 12 de novembro de 2001. Disponível em: https://www. oab.org.br/jurisprudencia/detementa/1406?title $=5584-2001$ pca\&sear$\mathrm{ch}=$ Idoneidade $\% 20$ moral $\% 20-\% 20$ condena $\% \mathrm{C3} \% \mathrm{~A} 7 \% \mathrm{C} 3 \% \mathrm{~A} 3 \mathrm{o} \% 20$ por\%20crime \%20de\%20homic\%C3\%ADdio. Acesso em: 3 nov. 2019.

CONSELHO FEDERAL DA ORDEM DOS ADVOGADOS DO BRASIL. Súmula n 09/2019/COP. Requisitos para a inscrição nos 
quadros da Ordem dos Advogados do Brasil. Idoneidade moral. Prática de feminicídio ou de agressão evidente a mulheres. Proposta de edição de Súmula. Relator: Conselheiro Federal Rafael Braude Canterji. 2019. Disponível em: https:/catarinas.info/wp-content/uploads/2019/03/ Co\%CC\%81 pia-de-49.0000.2019.002283-2-Su\%CC\%81 mula-viole\%CC\%82ncia-contra-a-mulher.pdf. Acesso em: 22 abr. 2019.

CONSELHO FEDERAL DA ORDEM DOS ADVOGADOS DO BRASIL. Código de Ética e Disciplina da OAB. Brasília: DF; Conselho Federal da Ordem dos Advogados do Brasil, 2015. Disponível em: https://www.oab.org.br/arquivos/resolucao-n-022015-ced-2030601765. pdf. Acesso em: 18 abr. 2019.

CUNHA, Rogério Sanches; PINTO, Ronaldo Batista. Violência doméstica: Lei Maria da Penha (Lei 11.340) comentada artigo por artigo. 8. ed. Salvador: Juspudvm, 2019.

ESPÍNDOLA, Caroline. Dos direitos humanos das mulheres à efetividade da lei Maria da Penha. Curitiba: Appris, 2018.

FERREIRA, Patrício Fernando Vaz. Da adequada interpretação do Enunciado $\mathrm{CGU} \mathrm{n}^{\circ}$ 06. Processo administrativo disciplinar deve aguardar conclusão de processo penal?. Revista Jus Navigandi, Teresina, ano 18, n. 3600, 10 maio 2013. Disponível em: https://jus.com.br/artigos/24398. Acesso em: 3 nov. 2019.

GAMA, Alessandra S. da. Lei Maria da Penha esquematizada: Lei 11.340, de 7 de agosto de 2006. 2. ed. Rio de Janeiro: Ferreira, 2015.

GONZAGA, Álvaro de Azevedo; NEVES, Karina Penna; BEIJATO JUNIOR, Roberto. Estatuto da advocacia e novo código de ética e disciplina da OAB - comentados. 5. ed. Rio de Janeiro: Método, 2019.

LÔBO, Paulo. Comentários ao estatuto da advocacia e da OAB. 10. ed. São Paulo: Saraiva Jur, 2017.

LUZ, Valdemar P. da. Manual do advogado. 17. ed. Florianópolis: $\mathrm{OAB} / \mathrm{SC}, 2004$.

MACHADO, Alberto de Paula et al. Estatuto da advocacia e da OAB comentado. Curitiba: OAB, 2014.

MEDINA, Paulo Roberto de Gouvea. A independência das instâncias e o processo ético-disciplinar. Revista da OAB, n. 89, p, 111-1243, jul./ 
dez. 2009. Disponível em: https://www.oab.org.br/publicacoes/detartigo/15. Acesso em: 03 nov. 2019.

MORESCO, Celso Luiz. O Princípio da independência de jurisdição e a influência da sentença penal no direito administrativo. In: SEDEP. Campo Grande: SEDEP, 1998. Disponível em: http://www.sedep.com. br/artigos/o-principio-da-independencia-de-jurisdicao-e-a-influencia-da-sentenca-penal-no-direito-administrativ/. Acesso em: 3 nov. 2019.

RAMOS, Gisela Gondin. Estatuto da advocacia: comentários e jurisprudência selecionada. 7. ed. Belo Horizonte: Fórum, 2017.

SOARES NETO, Paulo Bryan Oliveira. Comentários acerca das infrações e sanções disciplinares dispostas no Estatuto da Advocacia e da OAB em seu artigo 34. Revista Jus Navigandi, out. 2017. Disponível em: https://jus.com.br/artigos/61232/comentarios acerca-dasinfracoes-e-sancoes-disciplinares-dispostas-no-estatuto-da-advocaciae-da-oab-em-seu-artigo-34. Acesso em: 3 nov. 2019.

VIEIRA, Hélio; CERNOV, Zênia. Estatuto da OAB, regulamento geral e código de ética: interpretados artigo por artigo. São Paulo: Ltr80, 2016.

Recebido em: 11/05/2020

Aprovado em: 27/07/2020 